i.e. affecting the gas flow incoming towards an aircraft with an applied magnetic field The potential of MHD flow control system has been studied and demonstrated on numerous occasions [1][2][3], however it's prospective effectiveness remains an open question. With the new challenges facing aerospace industry in the upcoming decade comes a need for more advanced numerical simulation tools.

\section{Numerical Simulation of High-Speed Non- equilibrium Flow with Applied Magnetic Field}

1,2A.I. Ryakhovskiy < alexey.i.ryakhovskiy@mail.ioffe.ru>

1,2A.A.Schmidt $<$ alexander.schmidt@mail.ioffe.ru>

${ }^{2}$ V.I. Antonov< antonovvi@mail.ru > ${ }^{1}$ Ioffe Institute

Polytechnicheskaya st., 26, Saint-Petersburg, 194021, Russian Federation ${ }^{2}$ Peter the Great St.Petersburg Polytechnic University

Polytechnicheskaya st., 29, Saint-Petersburg 195251, Russian Federation

Abstract. The paper describes the development and testing processes of a modification of an existing solver for hypersonic reacting flow within the OpenFOAM numerical simulation framework. The modification is suited to simulate the interaction between the flow and the constant applied magnetic field. The purpose of the development is to create a simulation tool for the study of the concept of magnetohydrodynamical flow control and its possible technological applications. Resulting application utilizes Navier-Stokes-Fourier system of equations supplemented with appropriate auxiliary models for the accurate assessment of process-specific additional terms. Solver testing has been carried out using the cases that highlight solvers capabilities to model MHD high-speed flow in different regimes.

Keywords: numerical simulation; fluid flow control; magnetohydrodynamics; aerodynamics; shock waves

DOI: $10.15514 /$ ISPRAS-2017-29(6)-19

For citation: Ryakhovskiy A.I., Schmidt A.A., Antonov V.I. Numerical Simulation of HighSpeed Non-equilibrium Flow with Applied Magnetic Field. Trudy ISP RAN/Proc. ISP RAS vol. 29, issue 6, 2017, pp. 299-310. DOI: 10.15514/ISPRAS-2017-29(6)-17

\section{Introduction}

In the recent years there has been a resurgence of interest towards plasma-assisted technology in high-speed flight. Prospective applications of this technology include aerobraking, communication blackout mitigation, aerodynamics heating reduction, wave drag and turbulence cancelation and scramjet engine intake control. The principal idea behind most of these concepts is magnetohydrodynamic (MHD) control
Near space is the region of the atmosphere between controlled commercial airspace and the low earth orbit (LEO) [4]. This is the region where most of the aircraft with a potential to benefit from MHD flow control system operate. The difficulty of modeling the MHD interaction in hypersonic flow within the near space region is that the rarefaction of the gas can be high enough that the CFD model can become nonapplicable in some cases, yet DSMC-type (Direct Simulation Monte Carlo) can be too computationally prohibitive. The issue has to be addressed in developing a comprehensive simulation tool for the high-speed magnetohydrodynamic flow.

There are several simulation packages for hypersonic reacting flow, such as DPLR, LAURA, LeMANS, US3D and others. All of them, however, can only be distributed to and used by United States citizens or US government contractors. The challenge posed by this restriction can be answered by developing an open-source code for the use in high-speed non-equilibrium flow research and multiphysics problems associated with it.

\section{Development Basis}

We are using OpenFOAM CFD toolbox as a framework for out development because of its' flexibility, robust class structure for numerical simulation and a broad community of contributions. In previous works there have been attempts to use standard toolbox solvers to simulate magnetic field effect on the supersonic flow around the object [5]. However, OpenFOAM's basic kit lacks a dedicated solver for high-speed reacting flow. Due to this face we are basing our work on a solver, developed in the University of Strathclyde, Scotland [6] called hy2Foam. It combines the standard kit solvers rhoCentralFoam (density-based compressible flow solver based on central-upwind schemes of Kurganov-Tadmor) and reactingFoam (a solver for combustion with chemical reactions).

\section{Mathematical Model}

hy2Foam employs a Navier-Stokes-Fourier system of equations for reacting flow. To include a magnetic field interaction into the model the terms corresponding to Lorentz force and Joule heating have been added to the right hand sides of momentum and energy equation respectively. An important assumption needs to be made to allow for a reduction of the number of equations necessary to calculate the MHD terms Magnetic Reynolds number for the studied flow regimes is generally low, which allows us to disregard self-induced magnetic field [7]. This means that the only magnetic field present is the applied one, which eliminated the need to solve the 
Maxwell system of equations. The flux-divergence form of the resulting system is presented below.

$$
\frac{\partial \mathcal{U}}{\partial t}+\frac{\partial\left(\mathcal{F}_{i n v}+\mathcal{F}_{v i s c}\right)}{\partial x_{i}}=\mathfrak{W}
$$

$$
\boldsymbol{u}=\left(\begin{array}{c}
\rho \\
\rho_{s} \\
\rho u \\
\rho v \\
\rho w \\
\varepsilon_{v e, m} \\
\varepsilon
\end{array}\right), \mathcal{F}_{i n v}=\left(\begin{array}{c}
\rho u_{i} \\
\rho_{s} u_{i} \\
\rho u_{i} u+\delta_{i 1} p \\
\rho u_{i} v+\delta_{i 2} p \\
\rho u_{i} w+\delta_{i 2} p \\
\varepsilon_{v e, m} u_{i} \\
(\varepsilon+p) u_{i}
\end{array}\right), \mathcal{F}_{v i s c}=\left(\begin{array}{c}
0 \\
-\mathcal{J}_{s} \\
\tau_{i 1} \\
\tau_{i 2} \\
\tau_{i 3} \\
\varphi_{v, v i s c} \\
\varphi_{v i s c}
\end{array}\right), \boldsymbol{w}=\left(\begin{array}{c}
0 \\
\dot{\omega}_{s} \\
f_{i 1} \\
f_{i 2} \\
f_{i 3} \\
\dot{\omega}_{v, m} \\
Q_{m}
\end{array}\right)
$$

$\mathcal{F}_{\text {inv }}$ and $\mathcal{F}_{\text {visc }}$ correspond to inviscid and viscous components of the flux. A more detailed explanation of each term can be found in the original paper.

The magnetic terms are calculated using generalized Ohm's law. We need several of additional models for different associated physical phenomena to complete model. Among those are Landau-Teller model for trans-vibrational relaxation and MillikanWhite model for V-T relaxation times with Park's correction. Thermal diffusivities of different species are calculated using Eucken's formula. Mixture quantities are recovered using Gupta's mixing rule. Species' viscosity follows Blottner's formula. Diffusion and heat conduction are modeled by Fick's and Fourier's law respectively. Total pressure is recovered from partial pressures by Dalton's law [6]. Chemical reactions and their rated are taken from the paper by Park [7].

\section{A. Conductivity models}

Electrical conductivity of the flow plays a crucial role in estimating the intensity of the it's interaction with magnetic field. An electric conductivity model interface has been added to the hy 2 Foam, so that different conductivity model can be implemented and tested for use in high-speed flow problems. Five different electric conductivity models have so far been implemented alongside a dummy constant conductivity model. Two of them are semi-analytical Spitzer and Harm [8] and Chapman and Colwig [9] models. Another two models, developed originally by Bush [10] and Raizer [11] are semi-empirical. The fifth model was taken from the paper by Bityurin and Bocharov [1] and is based on Chapman-Enskog theory of multicomponent gas mixture. This last model is the most advanced and utilizes the gas mixture data that is available from solving Navier-Stokes-Fourier equations.
Table 1. Electric conductivity models

\begin{tabular}{|c|c|c|c|c|}
\hline Boltzmann & Spitzer-Harm & $\begin{array}{c}\text { Chapmann- } \\
\text { Cowling }\end{array}$ & Bush & Raizer \\
\hline$\frac{e^{2} n_{e} \tau_{e}}{m_{e}}$ & $\frac{c_{1, S} T^{\frac{3}{2}}}{\ln \left(c_{2, S} \frac{T^{\frac{3}{2}}}{\sqrt{n_{e}}}\right)}$ & $c \frac{\alpha}{Q \sqrt{T}}$ & $\sigma_{0}\left(\frac{T}{T_{0}}\right)^{n}$ & $c_{1, R} e^{-\frac{T_{1}}{T}}$ \\
\hline
\end{tabular}

\section{Test Results}

The developed code has been tested on a case from the book by Surjikov[12]. The case presents a hypersonic flow of molecular nitrogen around a cylinder with a 0.015 meters radius. Freestream conditions are presented in the table below.

Table 2. Surjikov case freestream conditions

\begin{tabular}{|l|l|l|}
\hline \multicolumn{1}{|c|}{ Quantity } & \multicolumn{1}{|c|}{ Value } & \multicolumn{1}{c|}{$\begin{array}{c}\text { Measurement } \\
\text { Units }\end{array}$} \\
\hline Pressure & 1300 & $\mathrm{~Pa}$ \\
\hline Temperature & 3030 & $\mathrm{~K}$ \\
\hline Density & 0.0014 & $\mathrm{~kg} / \mathrm{m}^{3}$ \\
\hline Velocity & 10300 & $\mathrm{~m} / \mathrm{s}$ \\
\hline
\end{tabular}

To test the capabilities of our MHD modification we have added a magnetic field to be generated by a coil located inside the cylinder. The distribution of magnetic flux intensity generated by it is shown in a Fig. 1. 

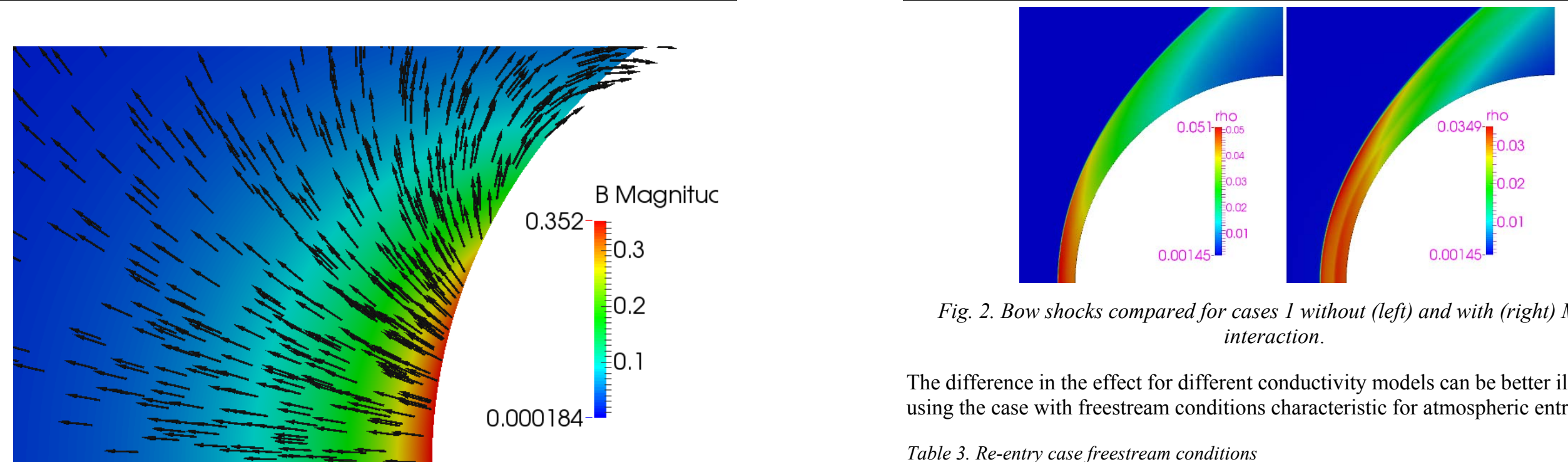

Fig. 2. Bow shocks compared for cases 1 without (left) and with (right) MHD interaction.

Fig. 1. Geometry of the case 1 and the distribution of magnetic flux density

Investigating this case with our MHD hypersonic solver serves 2 purposes. First, we can validate hy2Foam and its' auxiliary libraries on a well-known problem for which there are experimental data to use for comparison. Second, we can see how the modifications that we have added perform, when MHD interaction is introduced to the established case. Additionally, the numerical solution of the case with magnetic field interaction can give us insights on the potential of MHD control in the considered conditions.

The results for non-MHD case show good agreement with both experimental and numerical results from [10]. Apparent discrepancies can be attributed to the difference in choice of boundary conditions for temperature on the object (constant value in the source, zero gradient in our calculations) and using a different model for chemical reactions and their rates. The solution obtained for the case with magnetic interaction shows that without assisted ionization the effect of the applied magnetic field is negligible, albeit visible. Figures below show a clear increase of the shock standoff distance, the magnitude of which differs depending on model used to calculate electrical conductivity.

The difference in the effect for different conductivity models can be better illustrated using the case with freestream conditions characteristic for atmospheric entry.

Table 3. Re-entry case freestream conditions

\begin{tabular}{|l|l|l|}
\hline \multicolumn{1}{|c|}{ Quantity } & \multicolumn{1}{|c|}{ Value } & \multicolumn{1}{c|}{$\begin{array}{c}\text { Measurement } \\
\text { Units }\end{array}$} \\
\hline Pressure & 33 & $\mathrm{~Pa}$ \\
\hline Temperature & 200 & $\mathrm{~K}$ \\
\hline Density & 0.001 & $\mathrm{~kg} / \mathrm{m}^{3}$ \\
\hline Velocity & 5411 & $\mathrm{~m} / \mathrm{s}$ \\
\hline
\end{tabular}

The simulation results indicate that for these conditions the size and the parameter distribution within stagnation layer will vary significantly depending on the used electric conductivity model. The shock standoff distance can differ by as much as 2.5 times.

Results show that using both Spitzer-Harm and Raizer model can greatly exaggerate the MHD interaction effect. Bush model, on the other hand, considerably underestimates it compared to the other models. The remaining models provide similar results and can both be used reliably for this type of conditions.

Our third case serves to illustrate one of the applications of the concept. It is a model of a scramjet with a design Mach number of 10 . The freestream Mach number, however, is much lower, which results in a "shock spillage". This phenomenon is known to adversely affect the flight characteristics of the aircraft. The proposed solution is to use the magnetic field to preserve the position of oblique shock during the changes of flight regime. Similarly to our first test case we need to artificially increase the flow's electric conductivity to achieve the necessary intensity of the 
effect. For this purpose, we have used constant conductivity model. The location of inductor that generates the field is shown in the bottom picture of Fig. 6 .

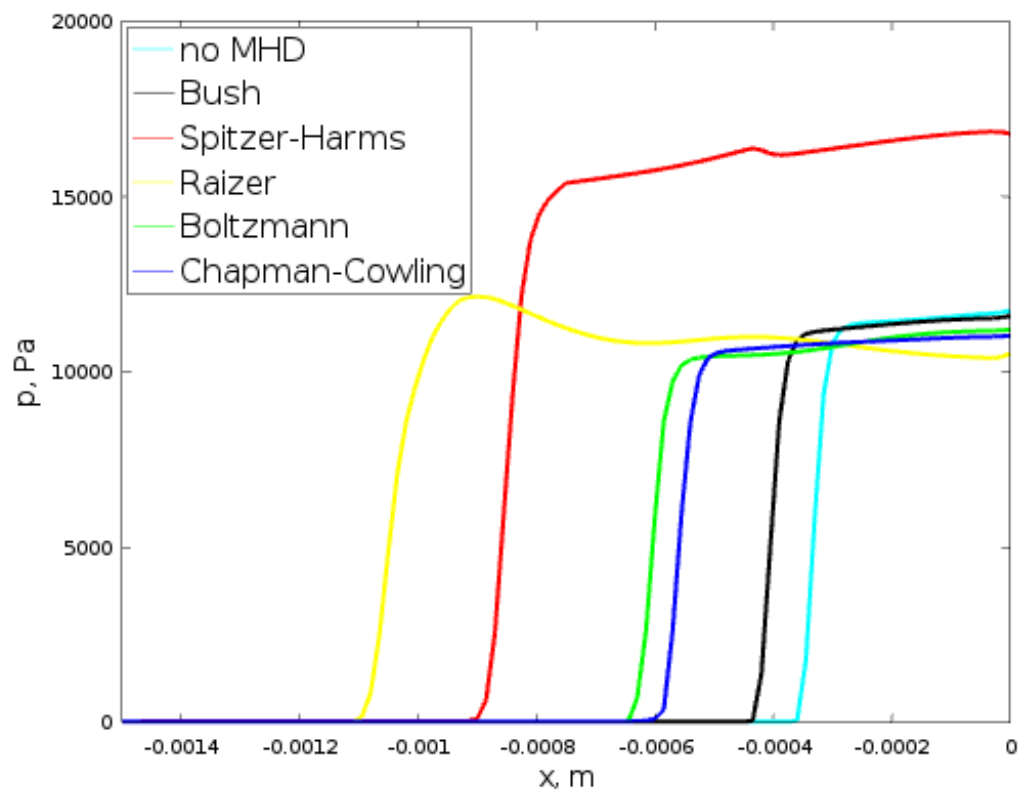

Fig. 3. Pressure distibution on the stagnation line, calculated using different conductivity models

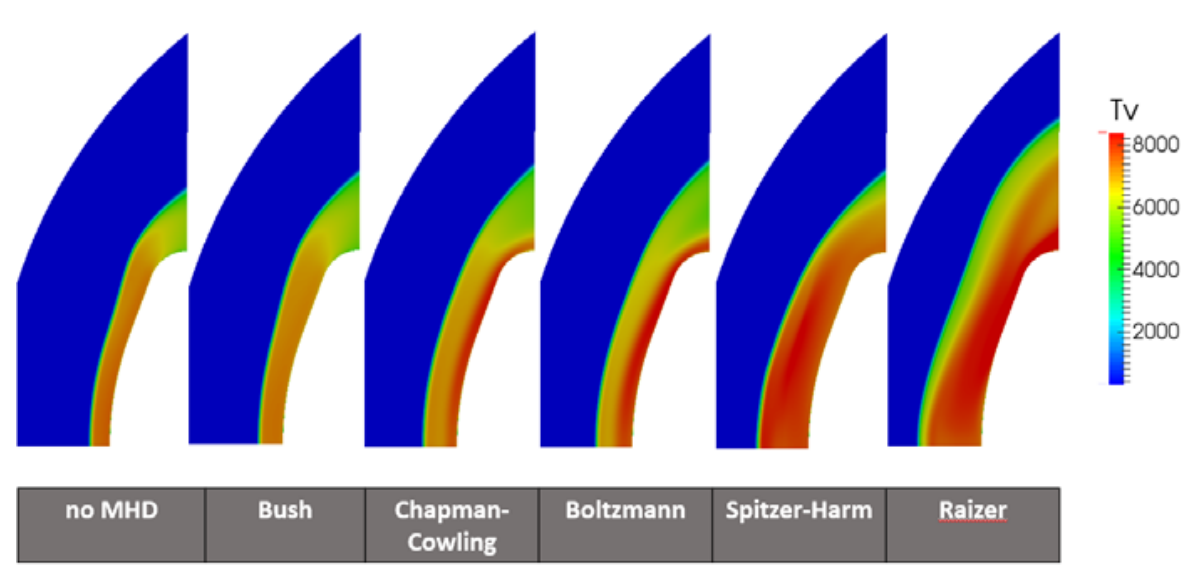

Fig. 4. Vibrational temperature distribution calculated using different electric conductivity models.
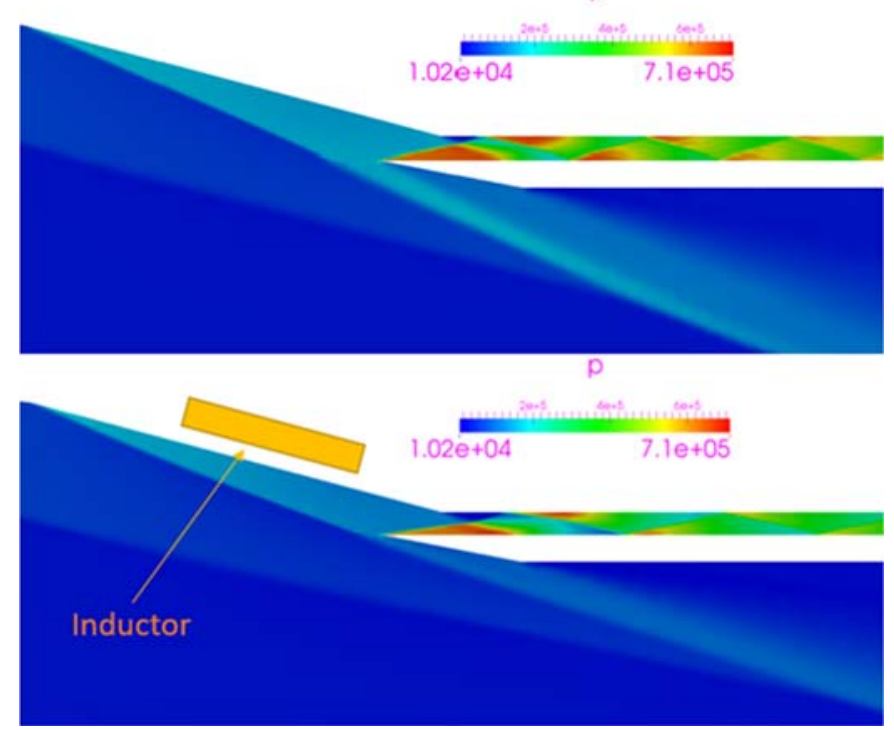

Fig. 5. Pressure distribution for scramjet case with and without MHD control effect

\section{Conclusion}

We have demonstrated that even at this stage of development the code can be used as a simulation tool by the researchers studying the interaction between the applied magnetic field and high-speed weakly ionized gas flow. Being developed within OpenFOAM framework the solver and it's auxiliary libraries can be easily modified and supplemented by anyone familiar with OpenFOAM structure, like it had been done by the authors of this paper with the solver's "parent" code hy2Foam.

Table 4. Scramjet case freestream conditions

\begin{tabular}{|l|l|l|}
\hline \multicolumn{1}{|c|}{ Quantity } & \multicolumn{1}{|c|}{ Value } & \multicolumn{1}{c|}{$\begin{array}{c}\text { Measurement } \\
\text { Units }\end{array}$} \\
\hline Pressure & 26436.3 & $\mathrm{~Pa}$ \\
\hline Temperature & 223.150 & $\mathrm{~K}$ \\
\hline Density & 0.412707 & $\mathrm{~kg} / \mathrm{m}^{3}$ \\
\hline Velocity & 1800 & $\mathrm{~m} / \mathrm{s}$ \\
\hline
\end{tabular}

The results of simulations provide an example of how the electric conductivity models can be tested for use in modeling of MHD hypersonic flow control with the developed software. They also showcase the potential effect of MHD flow control system on the 
shockwave configuration and the applications this effect might have in hypersonic aircraft design.

Further development of the code is going to include additional models for the electric conductivity flow and the processes related to the assisted ionization of the flow. I may also be necessary to develop a hybrid Direct Simulation Monte-Carlo - CFD code to adequately simulate MHD control of the flow around atmospheric entry vehicles, which is another potential application of this technology.

\section{References}

[1]. V. Bityurin, A. Bocharov, and J. Lineberry. MHD flow control in hypersonic flight. AIAA Paper, 3225, 2005.

2]. T. Fujino, T. Yoshino, and M. Ishikawa. Numerical Analysis of Reentry Trajectory Coupled with Magnetohydrodynamics Flow Control. Journal of Spacecraft and Rockets, 45(5), 911, 2008

[3]. N. Bisek, I. Boyd, and J. Poggie. Numerical study of plasma-assisted aerodynamic control for hypersonic vehicles. Journal of Spacecraft and Rockets, 46(3), 568, 2009

[4]. E. Allen. The Case for Near Space. Aerospace America, February 2006

[5]. A. Ryakhovskiy, and A. Schmidt. MHD supersonic flow control: OpenFOAM simulation. Trudy ISP RAN / Proc. ISP RAS, vol, 28, issue 1, 2016, pp. 197-206. DOI: 10.15514/ISPRAS-2016-28(1)-11

[6]. V. Casseau, R. Palharini, T. Scanlon, and R. Brown. A two-temperature open-source CFD model for hypersonic reacting flows, part one: zero-dimensional analysis. Aerospace, vol. 3(4), 2016.

[7]. I. Sarris, G. Zikos, A. Grecos, A. P., and N. Vlachos. On the limits of validity of the low magnetic Reynolds number approximation in MHD natural-convection heat transfer. Numerical Heat Transfer. Part B: Fundamentals, 50(2), pp. 157-180, 2006

[8]. L. Spitzer and R. Härm. Transport phenomena in a completely ionized gas. Physical Review, 89(5), 977, 1953.

[9]. S. Chapman. and T. Cowling. The mathematical theory of non-uniform gases: an account of the kinetic theory of viscosity, thermal conduction and diffusion in gases. Cambridge university press, 1970.

[10]. Bush, W. B. Magnetohydrodynamic - Hypersonic Flow Past a Blunt Body. Journal of Aero/Space Sciences, Vol. 25, No. 11, November 1958, pp. 685-690.

[11]. Raizer, Y. P., Gas Discharge Physics, Springer-Verlag, 1991

[12]. S. Surzhikov. A computational study of aerothermodynamics of hypersonic flow around dull bodies using the example of analysis of experimental data. M.: IPMech, 2011, $74 \mathrm{p}$. (in Russian)

\section{Численное исследование высокоскоростного неравновесного течения с приложенным магнитным} полем

1,2A.И. Ряховский < alexey.i.ryakhovskiy@mail.ioffe.ru>
1,2A.A. Шмидm <alexander.schmidt@mail.ioffe.ru>

${ }^{2}$ B.И. Антонов< antonovvi@mail.ru>

$$
{ }^{1} \text { ФТИ им. А.Ф. Иоффе }
$$

Политехническая ул., 26, Санкт-Петербург, 194021, Российская Федераџия ${ }^{2}$ Санкт-Петербургский Политехнический Университет Петра Великого

Политехническая ул., 29, Санкт-Петербург, 195251, Российская Федераџия

Аннотация. Статья описывает разработку и тестирование модификации решателя для гиперзвукового реагирующего течения в среде численного моделирования OpenFOAM. Модификация создается для моделирования взаимодействия между течением и приложенным постоянным магнитным полем. Цель разработки - создать численный инструментарий для исследования концепции магнитогидродинамического управления потоком и его возможных применений. Создаваемое приложение использует математическую модель на основе уравнений Навье-Стокса, дополненных необходимыми вспомогательными моделями для описания сопряженных процессов. Тестирования решателя проводилось на задачах, демонстрирующих основные возможности созданного приложения в моделировании высокоскоростных МГДтечений различных режимов. Тестовые примеры представляют собой задачи обтекания двумерных плоско и цилиндрически симметричных тел, имеющих форму, характерную для аппаратов, для которых известны потенциальные способы применения МГД управления. Исследовалось влияние выбора модели электропроводимости на результаты численного моделирования. Сравнение результатов показало зависимость важности выбора модели электропроводимости от разреженности рассматриваемого газового потока.

Ключевые слова: численное моделирование; управление потоком; магнитогазодинамика; неравновесные течения; ударные волны

DOI: $10.15514 /$ ISPRAS-2017-29(6)-19

Для цитирования: Ряховский А.И., Шмидт А.А., Антонов В.И. Численное исследование высокоскоростного неравновесного течения с приложенным магнитным полем. Труды ИСП РАН, том 29, вып. 6, 2017 г., стр. 299-310 (на английском языке). DOI: 10.15514 /ISPRAS-2017-29(6)-19

\section{Список литературы}

[1]. V. Bityurin, A. Bocharov, and J. Lineberry. MHD flow control in hypersonic flight. AIAA Paper, 3225, 2005.

[2]. T. Fujino, T. Yoshino, and M. Ishikawa. Numerical Analysis of Reentry Trajectory Coupled with Magnetohydrodynamics Flow Control. Journal of Spacecraft and Rockets, 45(5), 911, 2008 
[3]. N. Bisek, I. Boyd, and J. Poggie. Numerical study of plasma-assisted aerodynamic control for hypersonic vehicles. Journal of Spacecraft and Rockets, 46(3), 568, 2009.

[4]. E. Allen. The Case for Near Space. Aerospace America, February 2006,

[5]. A. Ryakhovskiy, and A. Schmidt. MHD supersonic flow control: OpenFOAM simulation. Trudy ISP RAN / Proc. ISP RAS, vol, 28, issue 1, 2016, pp. 197-206. DOI: 10.15514/ISPRAS-2016-28(1)-11

[6]. V. Casseau, R. Palharini, T. Scanlon, and R. Brown. A two-temperature open-source CFD model for hypersonic reacting flows, part one: zero-dimensional analysis. Aerospace, vol. 3(4), 2016.

[7]. I. Sarris, G. Zikos, A. Grecos, A. P., and N. Vlachos. On the limits of validity of the low magnetic Reynolds number approximation in MHD natural-convection heat transfer. Numerical Heat Transfer. Part B: Fundamentals, 50(2), pp. 157-180, 2006.

[8]. L. Spitzer and R. Härm. Transport phenomena in a completely ionized gas. Physical Review, 89(5), 977, 1953.

[9]. S. Chapman. and T. Cowling. The mathematical theory of non-uniform gases: an account of the kinetic theory of viscosity, thermal conduction and diffusion in gases. Cambridge university press, 1970.

[10]. Bush, W. B. Magnetohydrodynamic - Hypersonic Flow Past a Blunt Body. Journal of Aero/Space Sciences, Vol. 25, No. 11, November 1958, pp. 685-690.

[11]. Raizer, Y. P., Gas Discharge Physics, Springer-Verlag, 1991

[12]. С. Суржиков. Расчетное исследование аэротермодинамики гиперзвукового обтекания затупленных тел на примере анализа экспериментальных данных. М.: ИПМ им. АЮ Ишлинского РАН, 2011, 84 стр. 